\title{
LA LIBERTAD FEMENINA EN LAS INSTITUCIONES RELIGIOSAS MEDIEVALES
}

\author{
MARÍA-MILAGROS RIVERA GARRETAS \\ Universidad de Barcelona
}

\section{SUMARIO}

1. La dificultad de sexuar la Historia.- 2. La libertad femenina: el caso de la beata María García de Toledo (h. 1344-1426).

\section{LA DIFICULTAD DE SEXUAR LA HISTORIA}

La historia de las mujeres, su historiografía, se debate desde el siglo XIX con una dificultad que afecta particularmente a la época medieval: la de decidir si la monacación y la dedicación a la vida espiritual no reglada han de ser, en rigor, interpretadas como tentativas de liberación o como formas de opresión de las mujeres por los hombres. Detrás de esta dificultad se oculta otra de mayor envergadura: la dificultad -imposibilidad incluso- de pensar el mundo, las formaciones sociales y su historia, en dos; es decir, en femenino y en masculino. En otras palabras, la dificultad de tener metódicamente en cuenta las relaciones de los sexos (además de las relaciones entre los sexos) cuando se escribe historia general. Pues si bien la identidad humana es una, esta identidad - que es una entidad ficticia, una abstracción - no existe como tal en la historia. En la historia, la identidad humana 
se presenta siempre en dos: femenina y masculina. En la historia hay, y solo hay, mujeres y hombres'.

Estas dificultades afectan a la interpretación de la historia de la dedicación a la vida espiritual no reglada y del monacato femenino porque han tenido como consecuencia que el canon de libertad aplicado a la historia de esas experiencias de mujeres haya sido casi siempre el canon que resultaba significativo para la historia de la religiosidad de los hombres de su clase social. Un canon, por tanto, que no tiene mas que ocasionalmente en cuenta la evidencia de la diferencia sexual ${ }^{2}$. Una limitación canónica - consecuencia de la pérdida de capacidad significadora, en la escritura de historia, de la diferencia de ser mujer y de la diferencia de ser hombre-que no es propia de la Europa medieval sino del Occidente moderno y contemporáneo ${ }^{3}$.

Evocando una frase afortunada de Hegel, la filósofa de lengua francesa Luce Irigaray escribió en los años ochenta del siglo XX que "la diferencia sexual es uno de los problemas, o el problema, que nuestra época tiene que pensar"4. "Nuestra época" - dice- porque la necesidad que Irigaray señala es consecuencia más de una pérdida que de un logro nuevo del progreso humano.

En la Europa medieval, la sensibilidad a la potencia significante de la diferencia sexual tomó formas diversas. Una de ellas fue la cosmovisión en la que convivían dos principios creadores - femenino y masculino- de envergadura, cada uno de ellos, cósmica; lo cual no es -si se toma la libertad de apartarse del pensamiento único- una contradicción sino, más bien, una muestra de concordantia oppositorum. Esta cosmovisión pensada en dos ha sido yendo reemplazada, desde el siglo XIV, según indican las investigaciones de Teresa Gràcia, por otra en la que el principio masculino

\footnotetext{
'De la diferencia sexual como categoría de análisis filosófico han tratado: Luce IRIGARAY, Éthique de la différence sexuelle, París, Les Éditions de Minuit, 1985; DiótimA, Traer al mundo el mundo. Objeto y objetividad a la luz de la diferencia sexual, trad. de María-Milagros Rivera Garretas, Barcelona, Icaria, 1996; Geneviève FRAISSE, La différence des sexes, París, PUF, 1996; Françoise COLLIN y Marisa ForCINA, La differenza dei sessi nella filosofia. Nodi teorici e problemi politici, Lecce, Milella, 1997.

${ }^{2}$ Sobre esta cuestión, véase Dı́́tıMA, Il pensiero della differenza sessuale, Milán, La Tartaruga, 1987.

${ }^{3}$ Luisa Muraro, Guillerma y Maifreda. Historia de una herejía feminista, trad. de Blanca Garí. Barcelona, Omega, 1997, XVI. David F. NoBLE, $A$ World Without Women. The Christian Clerical Culture of Modern Science, Nueva York, Knopf, 1992.
}

${ }^{4}$ Luce IrIGARAY, Éthique, p. 13. 
absorbió al femenino; absorción que se manifiesta en la pretensión masculina de crear de la nada, prescindiendo de la materia. "A finales del siglo XIV," - ha escrito Teresa Gràcia- "institucionalizada la creación ex nihilo, el método inductivo análogo al proceso creativo físico, desvirtuado, se margina; el principio femenino autosuficiente a nivel cósmico, subsumido en el principio masculino, desaparece" ${ }^{\text {. }}$.

Otra forma fue la doctrina del "endiosamiento", doctrina que Luisa Muraro ha definido como "casi una herejía"6. Investigando en torno a la que pudo ser la enseñanza de Guillerma de Bohemia en la Milán del siglo XIII, una enseñanza distinta de la herejía guillermita que le siguió, esa filósofa la ha asociado con la de otra gran beguina y teóloga en lengua materna del mismo siglo XIII, Margarita Porete, la autora del Espejo de las almas simples $^{7}$. Habla Luisa Muraro de la doctrina del endiosamiento en Guillerma y en Margarita y considera que algo tuvo que ver esta doctrina con la herejía amalriciana. La herejía, pues, de Amalrico de Bène (m. 1206), que fue condenada por el sínodo de París de 1210, junto con una traducción y comentarios a Aristóteles de David de Dinant, y ciertos "libros teológicos" escritos en lengua materna (in Romano dice el texto de la condena) ${ }^{8}$. Lo que los obispos de ese sínodo de París temían de estas tres fuentes de problemas para ellos era que sostenían la divinidad de la materia, no solo de la forma, en los cuerpos; materia que mucho suele tener que ver en el discurso filosófico y teológico con la madre y la mujer. Una doctrina, la de la divinidad (¿endiosamiento?) de la materia, contraria a lo que el coetáneo de Guillerma de Bohemia (m. 1281) y de Margarita Porete (quemada el 1 de junio de 1310), Tomás de Aquino (1225-1274), establecería más tarde como

\footnotetext{
${ }^{5}$ Teresa GràCIA SAHuQUILlo, Principi femeni "versus" Principi masculí (s. XIII-XIV). (Una experiència de lectora). Seminario "El impacto del Humanismo en las relaciones sociales entre los sexos. De la mística del S. XIV a la caza de brujas", Centro Duoda, Universitat de Barcelona, 28 febrero 1997.

${ }^{6}$ Luisa MURARo, Margarita Porete y Guillerma de Bohemia (la diferencia femenina, casi una herejía), "Duoda. Revista de Estudios Feministas" 9 (1995), pp. $81-97$ (reimp. en apéndice a EAD., Guillerma y Maifreda, pp. 195-208)

${ }^{7}$ Margarita PORETE, El espejo de las almas simples y ANÓNIMO, Hermana Katrei, trad. de Blanca Garí y Alicia Padrós-Wolff, Barcelona, Icaria, 1995. La descubridora de la autoría de Margarita fue Romana GUARNIERI, Il movimento del Libero Spirito, Roma, Edizioni di Storia e Letteratura, 1965 ["Archivio Italiano per la Storia della Pietă", 4].

${ }^{8}$ Sobre el impacto de la escritura de teología en lengua materna en la Europa del siglo XIII, véase: Luisa MURARO, Lingua materna scienza divina. Scritti sulla teologia mistica di Margherita Porete, Nápoles, D’Auria, 1995. Me dice Peter Dronke, conversando, que el latín deja de ser lengua materna en el siglo VII.
} 
ortodoxia católica, recuperando la dicotomía jerárquica de Aristóteles entre materia y forma; pero que en ese momento, principios del siglo XIII, no era condenada - la idea de la divinidad de la materia- por el papa Inocencio III (1198-1216) ${ }^{9}$. Negándole divinidad a la materia, algunos pretenden forzar el ingreso de la diferencia de ser mujer y de la diferencia de ser hombre, en el pensamiento binario, un pensamiento que empequeñece la vida.

En el origen de la controversia medieval en torno a la dimensión infinita del principio creador femenino - la materia - se puede situar el conflicto histórico entre dos imágenes de Dios - la pagana y la cristiana-; un conflicto que representan, por ejemplo, las visiones de Vibia Perpetua a principios del siglo III $^{10}$. Un conflicto cuyos componentes pervivieron en lo inconsciente colectivo medieval, aflorando en movimientos espirituales juzgados, unos, heréticos por la Iglesia, y exponente, otros, de las experiencias unitivas más célebres y bellas de la mística cristiana.

Son indicio de este gran conflicto histórico algunas vacilaciones -o aparentes vacilaciones - de la historiografía feminista especializada en la interpretación de la religiosidad y de la espiritualidad femeninas; vacilaciones que se pueden manifestar en una sola autora. Ida Magli, por ejemplo, gran conocedora y crítica de la historia del cristianismo, ha sido, por una parte, pionera en sostener en una enciclopedia católica la capacidad liberadora del monacato femenino y su irreducibilidad al monacato masculino ${ }^{11}$; mientras que, por otra, abomina del trato que la Iglesia católica les ha otorgado y otorga a ellas ${ }^{12}$. Escribe en el primer sentido: "Así pues, la inclinación de la mujer al ascetismo, que el monacato cristiano propone (...) revela su significado profundo de rebelión por todos los aspectos que liberan a la mujer de sus funciones culturales: negación del matrimonio, sublimación del sexo mediante la virginidad, rechazo, mediante la ascesis, de la valoración de la comida y de todas las actividades relacionadas con la comida y lo

${ }^{9}$ Enzo Maccagnolo, David of Dinant and the Beginnings of Aristotelianism in Paris, en Peter Dronke, ed., A History of Twelfth Century Western Philosophy, Cambridge, Cambridge University Press, 1988, pp. 429-442.

${ }^{10}$ Sigo la interesante interpretación de Marie-Louise von Franz, Passio Perpetuae, Zürich, Daimon Verlag, 1951.

"Ida MAGLI, Monachesimo femminile, reimp. en Serena CASTALDI y Liliana CARUSO, eds., L'altra faccia della storia, quella femminile, Florencia, D'Anna, 1975, pp. 125-132.

${ }^{12}$ Ida MAGLI, Storia laica delle donne religiose, Milán, Longanesi, 1995; EAD., De la dignidad de la mujer. La violencia contra las mujeres, el pensamiento de Wojtyla, trad. de Belén Garí, Barcelona, Icaria, 1995. 
doméstico, recuparación de la propia "potencia" en un vínculo con lo sagrado que, en el monacato, ya no necesita mediaciones sacerdotales masculinas"13. Escribe, en cambio, en el segundo sentido: "La violencia que se ejerce contra las mujeres, eligiendo para ellas o marido o convento durante casi toda la historia de Europa, desde el reconocimiento del cristianismo como religión del Estado hasta el desarrollo completo del pensamiento laico y la disminución del poder de la Familia (...) sobre la vida de las hijas (...) es muy difícil de narrar porque pertenece a la estructura normal de una sociedad, en la cual la casta religiosa no es solo parte integrante sino dirigente" 14 .

Hay aquí un enigma, un verdadero callejón sin salida historiográfico. Porque se ve liberación en dejar de ser lo que se es (mujer), en anular las facultades y potencias recibidas gratis et amore de la madre al nacer; y hacerlo, además, masivamente, ya que se proclama al mismo tiempo al cristianismo como "religión de las mujeres"15.

Pienso que de este callejón se vislumbra una salida si se deja que intervenga en el juego interpretativo una instancia, con frecuencia olvidada, que es la posibilidad de existencia histórica de libertad femenina ${ }^{16}$. Libertad de ella irreducible a la libertad de él ${ }^{17}$.

Cuando es posible pensar el mundo en $\operatorname{dos}^{18}$, resulta que la libertad (como quienes hacen historia o quienes hacen política o quienes van por la calle) no es neutra sino sexuada; no determinísticamente ${ }^{19}$, sino indicando tendencias en el tiempo, tendencias en proceso de conservación y de cambio, como es habitual en la historia. Ocurre entonces que se abren a la percepción

\footnotetext{
${ }^{13}$ Ida MAGLI, Monachesimo femminile, pp. 125-126.

${ }^{14}$ EAD., Storia laica, p. 125.

${ }^{15}$ Ibid., p. 7.

${ }^{16}$ En la formulación contemporánea de la libertad femenina ha sido fundamental el texto: Librería de mujeres de Milán, Un filo di felicità, "Sottosopra" (enero 1989). Un ejemplo -entre otros- de historia de las mujeres que no tiene apenas en cuenta la posibilidad de libertad de ellas: Georges DUBY y Michelle PERROT, eds., Historia de las mujeres en Occidente, trad. Madrid, Taurus, 1992.

${ }^{17} \mathrm{He}$ tocado este tema, en lo referido a la cuestión de los renacimientos, en Escribir $y$ enseñar historia al final del patriarcado, "Duoda", 15 (1998), pp. 13-26.

${ }^{18}$ No me refiero a dualismos tipo bien/mal, que no es dualidad sino oposición binaria.

${ }^{19} \mathrm{El}$ largo y famoso debate en torno al esencialismo, muy vivo entre polemistas de lengua inglesa, ha resultado ser un debate escolástico, de poca sustancia, que el tiempo apagó sin más. [Lo he tocado en Feminismo de la diferencia. Partir de sí, "El viejo topo", 73 (marzo 1994), pp. 31-35].
} 
espacios de realidad y espacios de historia hasta entonces ocultos o velados por un régimen del uno que fuerza, abstrayéndolo, lo real ${ }^{20}$. Se distingue entonces, por ejemplo, entre libertad individualista y libertad relacional (la segunda, más femenina que masculina), enriqueciendo esta distinción la escritura de historia ${ }^{21}$.

En el proceso de pérdida de potencia significadora del principio creador femenino está inscrita una confusión: la que ha llevado a creer que relación de los sexos es lo mismo que relación entre los sexos. Se intercambia el "de los sexos" por "entre los sexos"; lo cual quiere decir que "relación de los sexos" es hoy, con frecuencia, una frase incomprensible y, por tanto, un pensamiento insignificante ${ }^{22}$.

Relación de los sexos es relación de cada uno de los sexos con su infinito propio: dos infinitos que la filosofía abstrae en una "identidad humana"; identidad que así resulta ser una, mientras que los sexos son siempre y solo dos. Relación de los sexos que "no puede quedar pagada / sino con Divinidad"23; porque ella tiene su infinito propio, su posibilidad de ser en el tiempo, irreducible al infinito y a la posibilidad de ser en el tiempo de él. Relación entre los sexos es, en cambio, la que se contrata, se impone o se acepta con esta o con aquel, para entenderse o desentenderse, para ejercer o rechazar instancias de poder, para luchar, para procrear, para inspirarse, para divertirse, para estar en la sociedad... Las dos relaciones son susceptibles de historia; con la diferencia de que la primera no entra en el pensamiento binario, mientras que la segunda, sí.

\footnotetext{
${ }^{20}$ María Zambrano escribió de este proceso en muchas de sus obras; por ejemplo, en Filosofía y poesía (1939), Madrid, Universidad de Alcalá y Fondo de Cultura Económica, 1993, y en Claros del bosque (1977), Barcelona, Seix Barral, 1990.

${ }^{21} \mathrm{El}$ concepto de libertad relacional en Lía Cigarini, Libertad femenina y norma, "Duoda", 8 (1995), pp. 85-90.

${ }_{22}^{2}$ Por eso - pienso- el título La différence des sexes, de Geneviève FraISSE, ha sido traducido al italiano como La differenza tra $i$ sessi (Turín, Bollati Boringhieri, 1996).

${ }^{23}$ San JUAN DE LA CRUZ, Poesía completa y comentarios en prosa, ed. de Raquel Asún, Barcelona, Planeta, 1997, p. 38.
} 


\section{LA LIBERTAD FEMENINA: \\ El CASO DE la beata María GaRcía DE TOlEDO}

(H. 1344-1426)

Cuando, al analizar las fuentes históricas, se deja entrar en el juego interpretativo la posibilidad de libertad femenina, comparecen relaciones sociales que, sin ella, resultan invisibles o difíciles de reconstruir verazmente. Cuando se analizan las fuentes referidas a la experiencia religiosa (una experiencia frecuente en la historia de las mujeres de Occidente) ${ }^{24}$ resulta que tanto la religiosidad como la espiritualidad no reglada han sido durante mucho tiempo dos de las mediaciones históricas que algunas (muchas, bastantes) mujeres han encontrado para existir y decirse libremente. Luisa Muraro lo descubrió estudiando el proceso inquisitorial contra Guillerma de Bohemia (del 1300): "En quienes se le aproximaron" - ha escrito- "y en los hechos e ideas que se asocian con su nombre, es posible captar el signo que ha dejado su potencia humana femenina. Intentar leer esos signos" - prosigue- "era lo que me quedaba más cerca y es a la vez lo que considero más importante para mi sexo: significarse"25.

Desde el medievalismo, Lina Eckenstein, por ejemplo, en una obra erudita ya clásica, había descubierto en el monacato femenino espacios de libertad de las mujeres. Un siglo después de la publicación de esta obra, un grupo de historiadoras de lengua italiana ha estudiado la capacidad civilizadora de algunos espacios femeninos medievales en los que fue posible la libertad ${ }^{26}$.

Lo más común en la historiografía ha sido, sin embargo, la atribución sin crítica a la religiosidad y espiritualidad femeninas de los rasgos de las masculinas ${ }^{27}$. La religiosidad femenina - se dice para

\footnotetext{
${ }^{24}$ Lo indica Wanda TOMması en Simone Weil. Esperienza religiosa, esperienza femminile, Nápoles, Liguori, 1997.

${ }^{25}$ Luisa MURARO, Guillerma y Maifreda, p. XVII

${ }^{26}$ Lina ECKENSTEIN. Women under Monasticism 500-1500, Cambridge, Cambridge University Press, 1896. Marirì MARTINENGO y otras, Libere di esistere. Costruzione femminile di libertà nel Medioevo europeo, Turín, SEI, 1996. [Una recensión en "Duoda", 14 (1998), pp. 169-171].

${ }^{27}$ Así lo afirma John A. Nichols en su Introduction a Id. y Lillian T. SHANK, eds., Medieval Religious Women, I: Distant Echoes, Kalamazoo (MI), Cistercian Publications, 1984 pp. 1-9, esp. p. 3. Se deduce de Isabel del VAL VALDIVIESO, Las instituciones religiosas femeninas, "Acta Historica et Archaeologica Mediaevalia", 18 (1997), pp. 161-178.
} 
justificar este análisis- ha dejado menos fuentes que la masculina ${ }^{28}$. Fuentes, sin embargo, es obvio que hay ${ }^{29}$, y es con los datos que se conservan con lo que se suele escribir historia ${ }^{30}$. La dificultad, pienso, es, en realidad, del orden simbólico. Y consiste en no poder (no querer, tal vez) decir con palabras dotadas de autoridad que el mundo es uno y los sexos son dos, femenino y masculino ${ }^{31}$; siendo, por tanto, necesaria la mediación entre estos dos principios creadores de envergadura cósmica ${ }^{32}$.

Un ejemplo de libertad femenina en la historia es la vida de la beguina o beata del siglo XIV María García de Toledo ${ }^{33}$ : una noble de esta ciudad que dedicó unos setenta años de su larga vida a fundar y experimentar varias formas de espiritualidad en relación ${ }^{34}$; durante un siglo -el XIV - difícil para mujeres y hombres de espíritu libre, mujeres y hombres que se debatieron entre la hostilidad de la Inquisición católica y la perplejidad individualista y laica del Humanismo.

María García de Toledo fue escogida por su madre y su padre para la vida religiosa; por eso, a los doce años ingresó en el convento de benedictinas de San Pedro de las Dueñas de Toledo, "do era priora una su hermana que mucho la amaua":

A estos dio Dios entre otros hijos e hijas una hija mui graciosa, cunplida de toda hermosura, a la qual pusieron por nonbre María y el sobrenonbre del padre, conuiene a saber, doña Mari Garçía, a la qual sos padres, ansí

\footnotetext{
${ }^{28} \mathrm{John}$ NiCHOLS, por ejemplo, en Ibid., p. 2.

${ }^{29}$ Un ejemplo, las obras de María ECHÁniz SANS, Las mujeres de la Orden militar de Santiago en la Edad Media, Valladolid, Junta de Castilla y León, 1992 y EAD., El monasterio de Sancti Spiritus de Salamanca (1268-1500), Salamanca, Universidad de Salamanca, 1993.

${ }^{30}$ Excepto en proclamas revolucionarias como la del Manifesto di Rivolta Femminile (Roma 1970): "Consideriamo incompleta una storia che si è costituita sulle tracce non deperibili" (S CASTALDi y L. CARUSO, eds., L'altra faccia della storia, p. 5).

${ }^{31}$ El concepto de autoridad (que es distinta del poder) es de la comunidad filosófica Diótıma, Oltre l'uguaglianza. Le radici femminili dell'autorità, Nápoles, Liguori, 1995.

${ }^{32}$ Sobre la necesidad de la mediación, Librería de mujeres de Milán, El final del patriarcado, trad. de María-Milagros Rivera, Barcelona, Llibreria Pròleg, 1996, pp. 20-22.

${ }^{33}$ Entre la numerosa y desigual bibliografía sobre beguinas y beatas escojo dos bellos estudios: Angela MUÑOZ FERNÁNDEZ, Beatas y santas neocastellanas: Ambivalencias de la religión y políticas correctoras del poder (s. XIV-XVII), Madrid, Universidad Complutense y Comunidad de Madrid, 1994; y Blanca GARí y Alicia PADRós-WOLFF, Introducción a Margarita PORETE, El espejo de las almas simples, pp. 7-49.

${ }^{34}$ Referencia a los manuscritos de su biografía y un resumen de esta, interpretada desde la construcción social de la santidad, en Angela MUÑOZ FERNÁNDEZ, Beatas y santas, pp. 97-108.
} 
como la dézima parte de sus bienes, prometieron al Señor de toda uoluntad. Este uoto, quando ella fue de hedad de discreçión, no ansí como desobediente despreçio ni desecho con poco coraçón mas antes conforme con los padres lo confirmó; y ençendida en el amor del Señor, luego por obra lo cunplió de su propia uoluntad y de su libre aluedrío; sin consejo de alguna mas inspirada de don y graçia diuina, toda se ofreció al Señor ${ }^{35}$.

¿Hizo María de necesidad virtud o de necesidad libertad? El autor o la autora de su biografía (en autora hacen pensar frases como "sin consejo de alguna" o "nuestra amiga, nuestra conpanera María, cibdadana de Toledo) ${ }^{36}$ insiste en la libertad de la adolescente, dejando abierta a la historiografía cualquier opción interpretativa.

Una postura ideológica entendería sin vacilar que en la decisión de María García prevaleció la coacción. Esta lectura se atiene a un concepto individualista de libertad; un concepto de raíz cartesiana, anacrónico, en realidad, para interpretar muchas formas de vida de la sociedad feudal: una sociedad fundada en la relación múltiple entre gentes de condición jurídica libre y riqueza suficiente para hacer uso de esta condición. ¿Resulta, entonces, excéntrico pensar que una noble castellana del siglo XIV entendiera su libertad en relación, en relación también con el deseo de su madre y su padre? ${ }^{37}$ La instancia mediadora que puede transformar en libertad (que no virtud) la necesidad, es el amor.

Que María García de Toledo supo hacer de necesidad libertad lo indica el resto de su historia. Ya que no se dejó reducir, aunque sí atraer, por los demás proyectos de vida reglada que se le fueron ofreciendo, incluido el de los jerónimos, a los que dio dinero y con uno de cuyos fundadores, Pedro Fernández Pecha, tuvo una relación sororal durante el último tercio del siglo $\mathrm{XIV}^{38}$.

\footnotetext{
${ }^{35}$ Blblioteca de El Escorial, C-III-3, fol. 252-264; fol. 254r. Cito de este ms.

${ }^{36} \mathrm{Fol} .253 \mathrm{v}$. Esta forma de empatía carece de rigor positivista tanto como la que la entiende desde el deseo de hacerla suya de los jerónimos, una Orden en la que María García nunca entró.

${ }^{37}$ Esta posibilidad no cuestiona que, en las formaciones con contrato sexual (Carole Pateman, El contrato sexual, trad. Barcelona, Anthropos, 1995), las mujeres tengan menos privilegios y más obligaciones que los hombres de su clase social, como ha demostrado la historiografía feminista (sobre esto, puede verse mi Nombrar el mundo en femenino, Barcelona, Icaria, 1994).

38" Parecían otro san Francisco y otra santa Clara, otro san Xerónimo y otra santa Paula y Eustoquio" dice su biografía (fol. 259r).
} 
Pues tras unos años de estudio dejó el convento de San Pedro de las Dueñas, rechazó la propuesta de gobernar el de Santa Clara de Tordesillas y, sin hacer profesión religiosa, regresó a casa de su padre. Escogió entonces, en contra de la voluntad de padres y hermanos, vida de pobreza voluntaria; dedicándose a la mendicidad por Toledo en compañía de su aya doña Mayor Gómez, una viuda que ya no se separaría de ella:

\begin{abstract}
Andan entre'amas la vieja y su aia y la virgen tierna por toda la cibdad de casa en casa como pobres y peregrinas. Vienen entre los dos coros de la iglesia maior y allí, delante de todo el clero y pueblo, piden por amor de Dios limosna. Mucho se maravillan todos y dizen: "no auemos visto alguna que sea semejante a esta entre todas las henbras de aquesta çibdad. [...] Acaeçió un día que la dicha matrona biuda y la bendita uirgen, continuando su santa obra andando a demandar por las calles, encontraron con su padre y con el arçobispo su tío que hera hermano de su madre, aconpañado de muchos caualleros nobles; y como el arçobispo la viese ansí mendigar y la conoçiese, reprehendió a su cuñado porque consentía andar ansí despreçiada a su sobrina y díxole: "¡O uarón, como seas prudente! ¿Por qué consientes a moza tan pequeña, tan hermosa y generosa, andar ansí tan despreciada? ¿Por qué tienes tu hija ansí aboreçida? ¿Por qué no la casas con otro su igual?" Al qual respondió el noble cauallero benignamente: "¿Qué esposo puedo yo dar a mi hija más generoso y más rico que Ihesu Xhristo, hijo de Dios biuo? Dejémosla. Tomó para sí la mejor parte ${ }^{39}$.
\end{abstract}

De la pobreza voluntaria pasó María García de Toledo, "con otras muchas", a la villa de Talavera, cuyo dominio tenía entonces su padre. De ahí al pago de La Sisla, en el que hicieron una pequeña morada para dedicarse a la experiencia eremita.

Tras la muerte en 1369 del rey Pedro I (un rey que tiene en esta historia una papel confuso de perseguidor de mujeres), dejaron la vida eremítica y regresaron a Toledo, al beaterio de la "religiosa persona" doña María de Soria, en la parroquia de San Román. Más tarde, al morir sus padres, María García de Toledo compró, con la herencia de su madre, una casa en la parroquia de San Lorenzo; "y encerráronse ahí ella y aquella dueña ya dicha"40. Tenía entonces treinta y dos años aproximadamente.

\footnotetext{
${ }^{39}$ Ibid., 255v-256r.

${ }^{40} \mathrm{Fol} .257 \mathrm{v}$.
} 
Hizo su fama que "una honrrada dueña que se llamaua Teresa Vázquez, con otras siete mugeres continentes"4l acudieran a la casa y formaran juntas un grupo o comunidad de mujeres dedicado a la piedad y a la vida humilde de pobreza voluntaria; es decir, un beaterio. María García vivió en esta fundación suya, dirigiéndola, durante más de cincuenta años, hasta su muerte en $1426^{42}$. Esta "casa de las beatas llamadas de doña Marigarcía, que es en la çibdad de Toledo"43, siguió independiente hasta 1510, fecha en que fue legalmente incorporada a la Orden de San Jeróni$\mathrm{mo}^{44}$.

Los últimos folios de la biografía de María García de Toledo que conservamos, una biografía trasladada del latín al romance por el jerónimo Bonifacio de Chinchón en 1487, narran, sin embargo, un final de historia distinto: entre ambigüedades y cambios bruscos de estilo y de tiempos verbales que sugieren que no poco, efectivamente, "trasladó" el traductor su original, hace parecer a María García fundadora de la rama femenina de la Orden jerónima ${ }^{45}$. Cuando lo que ella hizo fue dar algo de su herencia para la fundación del monasterio jerónimo de La Sisla, enclavado en el pago en el que ella había, años antes, hecho, con otras, vida de ermitaña.

¿Documenta esta modificación de los hechos una cuestión de intereses político-religiosos? Pienso que no, pues no hubo conflicto entre María García de Toledo - mujer carismática- y los frailes fundadores de la Orden de San Jerónimo. Pienso que esta modificación de los hechos revela la dificultad, una dificultad del orden simbólico, de dar cabida en la concepción de lo religioso que se fragua en el siglo XV a formas de espiritualidad femenina enclavadas en una cosmovisión en la que había lugar para dos principios creadores de envergadura cósmica. Cuando Bonifacio de Chinchón "trasladó" la biografía de María García de Toledo (sesenta años después de la muerte de ella), los reinos hispánicos estaban emprendiendo

\footnotetext{
${ }^{41}$ Fol. 257v.

${ }^{42}$ Angela Muñoz Fernández, Beatas y santas, p. 105.

${ }^{43} \mathrm{Fol}$. 252r. En la parte norte de Toledo ubican José María QUADRADO y Vicente de la Fuente el convento de jerónimas "de San Pablo que fundó hacia 1404 la noble Da. María García de Toledo" (Toledo y Ciudad Real, reimp. Barcelona, El Albir, 1978, p. 280). La descripción arquitectónica indica que no es el edificio de la casa de las beatas, aunque coincida el solar (Fol. 252r, al margen, de otra mano "que aora se llama San Pablo").

${ }^{44}$ Angela MuÑoz FERnÁNDEZ, Beatas y santas, p. 107.

${ }^{45} \mathrm{Fol}$. 258r-264.
} 
el camino que les llevaría a ser paradigma del absolutismo - el reino de lo uno- durante la época de Felipe II; consumando un proceso de cierre de Europa iniciado con la "revolución aristotélica" de mediados del siglo $\mathrm{XIII}^{46}$. "El saber, el saber filosófico" - ha escrito María Zambrano- "ese del cual "todos los hombres tienen deseo natural", desembocó bien pronto en la forma cerrada y poderosa de la filosofía sistemática. Desde Santo Tomás ha sucedido de modo evidente y significativo. Dante y Santo Tomás, todo el siglo XIII, deja establecida y, podríamos decir, "cerrada" a Europa. Lo que va a seguir está ya en esas bases y es, en realidad, su despliegue, su desarrollo" ${ }^{47}$.

\section{RÉSUMÉ}

Je pars de la difficulté de l'historiographie des femmes pour décider si le monachisme et la contribution féminine à la vie spirituelle non réglée doivent être interprétés comme des tentatives de libération ou comme des formes d'oppression des femmes par les hommes. J'entends que cette difficulté d'interprétation n'est pas idéologique mais d'ordre symbolique. Je propose de considérer méthodiquement, l'orsqu'on écrit l'histoire générale, la différence sexuelle; c'est-à-dire, les relations des sexes, en plus des relations entre les sexes. La relation des sexes est la relation de chacun des sexes avec son propre infini: deux infinis que la philosophie abstrait dans une "identité humaine"; l'identité qui en résulte est toujours une tandis que les sexes sont toujours et seulement deux. Quand on considère la différence sexuelle, l'histoire des femmes contient, en plus d'oppression-libération, des variétés de liberté féminine qui enrichissent le récit de l'expérience historique.

\section{SUMMARY}

I set out from the difficulty in women's historiography of deciding whether the monastic life and the feminine dedication to the spititual life that is not regulated should be interpreted as attempts at liberation or as forms of oppression of women by men. I understand that this difficulty of interpretation is not ideological but rather of the symbolic order. I

\footnotetext{
${ }^{46}$ Así ha denominado Prudence ALLEN los efectos de la imposición como lectura obligatoria de las obras de Aristóteles en la Universidad de París en 1255 (EAD., The Concept of Woman. The Aristotelian Revolution 750 BC-AD 1250, Montreal y Londres, Eden Press, 1985.

${ }^{47}$ María Zambrano, Pensamiento y poesía en la vida española (1939), Madrid, Endymión, 1987, p. 29.
} 
propose that, when general history is written, sexual difference should be taken methodologically into account; that is to say, the relationships of the sexes as well as the relationships between the sexes. The relatioship of the sexes is the relationship of each one of the sexes with their own infinite: two infinites that philosophy abstracts into "human identity"; an identity that thus turns out to be one, whilst the sexes are always and only two. When sexual difference is taken into account, women's history contains, besides oppression-liberation, forms of feminine freedom that enrich the telling of historical experience. 